\title{
Long-term Complications of Congenital Esophageal Atresia-Single Institution Experience
}

\author{
M Koziarkiewicz, A Taczalska, I Jasiñska-Jaskula, H Grochulska-Cerska ANd A Piaseczna-Piotrowska \\ From the Department of Pediatric Surgery and Urology, Polish Mother's Health Center Research Institute in Lodz, Poland.
}

Correspondence to: Dr Maria Koziarkiewicz, Rzgowska 281/289, 93-338 Lodz, Poland. amaltea79@interia.pl

Received: July 02, 2014; Initial review: November 18, 2014; Accepted: April 10, 2015.
Objective: To evaluate general health condition of children operated for esophageal atresia, including complications from gastrointestinal tract and skeletal defects.

Methods: Between 1990 and 2005, 77 patients were operated for esophageal atresia in the Polish Mother's Health Memorial Hospital. The study was based on retrospective analysis of medical case records of all children with esophageal atresia. All living patients $(n=51)$ were invited for follow-up studies.

Results: Pathological gastroesophageal reflux was found in $46.7 \%$ of children. Scoliosis was diagnosed in 20 patients. Chest deformations were observed in $43.3 \%$ children

Conclusion: The absence of clinical symptoms does not exclude the presence of gastroesophageal reflux in children operated for esophageal atresia. Children operated for esophageal atresia should be followed up regularly by a multispecialistic medical team.

Keywords: Follow-up, Gastroesophageal reflux, Outcome, Scoliosis, Tracheo-esophageal fistula.

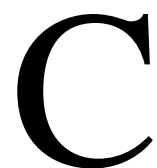

ongenital esophageal atresia has an incidence of 1:4500 live births [1]. With the improvement of surgical technique and advances in the pre- and post-operative care, mortality has decreased among affected children. Children who survive have late complications like gastroesophageal reflux (GER), recurrent respiratory infections, impaired lung ventilation, deformities of the chest and spine $[1,2]$, which can result both from the anatomical defect and from the implemented treatment $[3,4]$.

Our aim was to determine the prevalence of the most common long-term complications in children operated for esophageal atresia in our institution.

\section{Methods}

Between 1990 and 2005, 77 infants were operated for esophageal atresia at our institution. All 51 survivors (66.2\%) were invited between 2012 and 2013 for clinical evaluation. 30 children (58.8\%) took part in this study. Evaluation included: retrospective analysis of medical records; physical examination; and diagnostic tests viz., 24-hours esophageal pH monitoring, esophagography and an $X$-ray of the chest and spine. Cobb's angle was used to calculate the degree of curvature of the spine.

\section{RESULTS}

The mean age of the study group was 13.7 year (range 7-17 year, 76.7\% boys). 28 patients were operated in the first 1 3 day of life and in all of them esophago-esophageal anastomosis was performed. Tracheo-esophageal fistula was repaired in 24 patients (80\%). Two children with long gap atresia were operated at the age of 6 months. In $40 \%$ of cases, esophageal atresia was accompanied by other congenital defects (heart defects in 5, anal atresia in 2, and skeletal deformations in 5). 24-hour esophageal pH-metry was performed 3-4 months after surgery in 18 patients. GER was confirmed in 8 (44.4\%) children. Conservative treatment was sufficient to resolve symptoms of GER in all cases, there were no indications for surgery.

In all children, 24-hour pH-metry of the esophagus was performed during this study. Pathological GER was found in nearly half of the group out of which in almost 50\% GER was not seen in studies performed earlier (Table I). In 12 children (with pH-metry confirmed GER, 85.7\%) we performed esophagography and endoscopy of upper gastrointestinal tract. GER was confirmed in all children. Stenosis at the site of esophageal anastomosis was present in 8 patients $(66.7 \%)$.

In three children with confirmed GER, in whom histology of esophageal mucosa and submucosa samples demonstrated intestinal metaplasia $(n=2)$ or active inflammation $(n=1)$, conservative treatment was ineffective. They qualified for fundoplication. 
TABLE I Gastroesophageal RefluX (GER) IN THE Study $\operatorname{GrOUP}(N=30)$

\begin{tabular}{lll}
\hline Parameters & $\begin{array}{l}\text { GER } \\
n=14\end{array}$ & $\begin{array}{l}\text { No GER } \\
n=16\end{array}$ \\
\hline Symptoms of reflux & $8(57.1 \%)$ & $4(25 \%)$ \\
Choking episodes & $4(28.6 \%)$ & $1(6.3 \%)$ \\
Dysphagia & $4(28.6 \%)$ & $2(12.5 \%)$ \\
Recurrent respiratory infections & $6(42.9 \%)$ & $7(43.8 \%)$ \\
No GER workup & $2(14.3 \%)$ & $10(62.5 \%)$ \\
No prior GER diagnosis & $6(42.9 \%)$ & - \\
Long gap esophageal atresia & $2(14.3 \%)$ & 0 \\
\hline
\end{tabular}

GER-gastroesophageal reflux; all values in $n$ (\%).

Chest and spine $X$-rays demonstrated coexistence of esophageal defect and vertebral abnormalities (vertebral block, butterfly vertebrae, semivertebrae, spina bifida, additional vertebrae) in 6 (20\%), or rib anomalies (ribs block, deformed ribs, additional ribs) in 4 cases (13.3\%). Scoliosis was present in 20 (66.7\%) patients (isolated scoliosis in 10) with thoracic, thoracic-lumbar or lumbar in 12 and 4 patients, respectively. Two patients had thoracic and lumbar, and two had double thoracic scoliosis. Isolated chest deformity was present in 3 patients, and shoulder asymmetry and winged scapula in 11 patients each.

\section{Discussion}

Pathological gastroesophageal reflux is a significant clinical problem in patients after surgical repair of esophageal atresia [3]. It is associated with impaired esophageal motility, reduction in intra-abdominal portion of the esophagus, displacement of gastroesophageal junction and delayed gastric emptying [2,3,5]. These disorders may predispose to GER [3].

The incidence of GER in these patients ranges from 35 to $60 \%[4,5]$. Such significant differences are due to different criteria for diagnosis of reflux and time of performing the studies [3]. In the postoperative period, GER is observed in the majority of infants, which has been confirmed in our group. GER can appear at any age (even 5 years after surgery) and diagnostic methods should be repeated several times during child's development [3]. Symptoms of GER are found in $27-75 \%$ of patients with esophageal atresia [5-7]; dysphagia is the most common among the reported symptoms (85\%) [7,8]. A third of patients reported difficulty with swallowing of solid foods, but most of them did not use any dietary restrictions [6]

In our group, only half of children with GER had any clinical symptoms characteristic for reflux. This shows that the absence of clinical symptoms does not exclude the presence of GER. Small number of patients was a limitation of our study. It was impossible to perform statistical analysis towards the identification of GER risk factors.

According to Koivusalo, et al. [3], the only statistically significant factor having a relationship with the occurrence of GER, is large distance between the ends of the esophagus [3]. This observation has been confirmed by other authors [9]. In our group of children, primary esophageo-esophageal anasthomosis had been performed in all cases of GER. There is a weak correlation between clinical symptoms, macroscopic changes in the esophagus, and pathology results [6]. Therefore, in all patients after esophageal atresia repair, both $\mathrm{pH}$-metry and endoscopic examination of the upper esophagus are recommended [3].

In adults operated for esophageal atresia in the neonatal period, histology of samples obtained from the esophagus are normal in only 5\% [6]. There are reports on intestinal metaplasia and cancer in the esophagus of patients with GER operated for esophageal atresia in neonatal period [3,6-8]. Two of our patients underwent fundoplication because of intestinal metaplasia of the esophageal mucosa. Thus, endoscopic and $\mathrm{pH}$-metric monitoring of these patients for many years after surgery seems justified. However, endoscopy in patients without symptoms of GER is debatable [7,9]. As per literature, 23$64 \%$ of children require antireflux operation [4]. $18 \%$ of the operated patients, despite fundoplication, require pharmaco-therapy due to progression of histological changes in the esophagus [3].

Shoulder asymmetry, as a long term complication of surgery, is seen in as many as $80 \%$ of cases [10], and rib blocks at the site of thoracotomy are present in 30\% [11]. These abnormalities are most probably connected with thoracotomy and congenital vertebral and rib anomalies [10-14]. All of our patients were operated via posterolateral thoracotomy. As a result of denervation, flattening of the muscles occurred, due to decrease in their volume, as well as limitation of chest movements. Asymmetry and limited range of movement of the shoulder and sticking out shoulders are connected with denervation of latissumus dorsi, while chest deformations are connected with weakening of serratus muscle, rib adhesions and scoliosis $[10,14]$.

Prevalence of scoliosis in patients after esophageal atresia repair ranges from 6 to 50\% [14,15]. Scoliosis in this group is connected mainly with weakening of muscles due to partial damage to innervation, cut during thoracotomy, and presence of scars in the line of incision. The occurrence of lateral vertebral deformity is higher in patients after repeated thoracotomies [15]. The presence 
of pleural adhesions may also predispose to scoliosis $[12,15]$. This deformation is usually mild, not requiring operative treatment $[10,11]$. Risk factors for scoliosis include: narrowing of intervertebral spaces, ribs blocks and congenital vertebral anomalies [10-13]. It has been demonstrated that in $41.5 \%$ of patients with congenital vertebral deformations scoliosis develops [13].

We suggest that due to the occurrence of various late complications, children after repair of esophageal atresia should remain under long-term multispecialty medical care for many years. Diagnostic studies to identify GER should be repeated in children and young adults due to the possibility of late manifestation of reflux.

Contributors: MK: design of the study, collection of data, analysis and interpretation of data, literature search; AT: literature search, analysis and interpretation of data; IJ-J and HGC: examination of the patients; AP-P: conception and design of the study, drafting the article and revising it critically for important intellectual content, final approval of the version to be submitted.

Funding: None; Competing interests: None stated.

\section{REFERENCES}

1. Deurloo JA, Ekkelkamp S, Taminiau JA, Kneepkens CM, Ten Kate FW, Bartelsman JF, et al. Esophagitis and Barrett esophagus after correction of esophageal atresia. J Pediatr Surg. 2005;40:1227-31.

2. Kovesi T, Rubin S. Long-term complications of congenital esophageal atresia and/or tracheoesophageal fistula. Chest. 2004;126:915-25.

3. Koivusalo A, Pakarinen MP, Rintala RJ. The cumulative incidence of significant gastrooesophageal reflux in patients with oesophageal atresia with a distal fistula - a systematic clinical, $\mathrm{pH}$-metric, and endoscopic follow-up study. J Pediatr Surg. 2007;42:370-74.

4. Engum SA, Grosfeld JL, West KW, Rescorla FJ, Scherer LR 3rd. Analysis of morbidity and mortality in 227 cases of esophageal atresia and tracheoesophageal fistula over two decades. Arch Surg. 1995; 130:502 8.

5. Tovar JA, Diez Pardo JA, Murcia J, Prieto G, Molina M,
Polanco I. Ambulatory 24-hour manometric and pH metric evidence of permanent impairment of clearance capacity in patients with esophageal atresia. J Pediatr Surg. 1995;30:1224-31.

6. Deurloo JA, Ekkelkamp S, Bartelsman JF, Ten Kate FJ, Schoorl M, Heij HA, et al. Gastroesophageal reflux: prevalence in adults older than 28 years after correction of esophageal atresia. Ann Surg. 2003;238:686-9.

7. Taylor AC, Breen KJ, Auldist A, Catto-Smith A, Clarnette $\mathrm{T}$, Crameri J, et al. Gastroesophageal reflux and related pathology in adults who were born with esophageal atresia: a long-term follow-up study. Clin Gastroenterol Hepatol. 2007;5:702-6.

8. Sistonen SJ, Koivusalo A, Nieminen U, Lindahl H, Lohi J, Kero M, et al. Esophageal morbidity and function in adults with repaired esophageal atresia with tracheoesophageal fistula: a population-based long-term follow-up. Ann Surg. 2010;251:1167-73.

9. Guo W, Fonkalsrud EW, Swaniker F, Kodner A. Relationship of esophageal anastomotic tension to the development of gastroesophageal reflux. J Pediatr Surg. 1997;32:1337-40.

10 Sistonen SJ, Pakarinen MP, Rintala RJ. Long-term results of esophageal atresia: Helsinki experience and review of literature. Pediatr Surg Int. 2011;27:1141-49.

11. Sistonen SJ, Helenius I, Peltonen J, Sarna S, Rintala RJ, Pakarinen MP. Natural history of spinal anomalies and scoliosis associated with esophageal atresia. Pediatrics. 2009;124:e1198-204.

12. Dunlay RP, Jones KB, Weinstein SL. Scoliosis caused by rib fusion following thoracotomy for tracheoesophageal fistula: case report. Iowa Orthop J. 2007;27:95-8.

13. Chetcuti P, Myers NA, Phelan PD. Chest wall deformity in patient with repaired esophageal atresia. J Pediatr Surg. 1989;24:244-47.

14. Jaureguizar E, Vazquez J, Murcia J. Morbid musculoskeletal sequelae of thoracotomy for tracheoesophageal fistula. J Pediatr Surg. 1985;20:511-14.

15. Gilsanz V, Boechat IM, Birnberg FA. Scoliosis after thoracotomy for esophageal atresia. Am J Roentgenol. 1983;141:457-60. 